\title{
Geochemical constraints on the mid- ocean ridge hydrothermal flux of osmium to seawater
}

\author{
DREW D SYVERSON ${ }^{1}$, JOACHIM KATCHINOFF ${ }^{1}$, \\ LAUREL YOHE $^{1}$, BENJAMIN TUTOLO ${ }^{2}$, WILLIAM \\ SEYFRIED $^{3}$, NOAH J. PLANAVSKY ${ }^{1}$ AND ALAN \\ ROONEY ${ }^{1}$
}

${ }^{1}$ Yale University

${ }^{2}$ University of Calgary, Department of Geoscience

${ }^{3}$ University of Minnesota Twin Cities

Presenting Author: drew.syverson@yale.edu

The osmium (Os) isotope composition of seawater reflects a balance between isotopically distinct sources and sinks while providing pivotal insights into a range of Earth surface processes. In particular, the application of Os isotope stratigraphy in sedimentary successions has received considerable interest as a key tool for tracking changes in global weathering regimes and perturbations to the global carbon cycle throughout Earth history. However, our knowledge of the controls governing the flux of Os from mid-ocean ridge (MOR) hydrothermal systems remains limited. Constraints on this particular unradiogenic Os hydrothermal source to seawater could provide critical information on our interpretation of past geological events and their connection to the seawater Os isotope composition. This study will address these uncertainties by presenting experimental, geochemical modeling, and field data focusing on the partitioning of osmium between pyrite and seawater upon precipitation at conditions representative of MOR hydrothermal environments. Results indicate that dissolved Os strongly partitions into pyrite upon precipitation at experimental conditions. Integrating the experimentally determined $\mathrm{Os} / \mathrm{Fe}$ partition coefficient data into a geochemical model indicates that a significant amount of Os is retained within the subseafloor due to sulfide precipitation induced by mixing of conductively heated seawater with pristine high temperature hydrothermal fluids. These data suggest that the modern-day dissolved Os flux from high-temperature MOR hydrothermal environments is a minor source of Os to the oceans, resulting in the moderately radiogenic composition of modern-day seawater. However, the geochemical modeling results also indicate that the amount of sulfide mineral precipitation in the subseafloor of MOR systems is sensitive to the amount of sulfate $\left(\mathrm{SO}_{4}\right)$ and calcium $(\mathrm{Ca})$ in seawater. Thus, seawater chemistry will have a control on the degree of subseafloor sulfide precipitation and the flux of unradiogenic Os to seawater from mid-ocean ridge hydrothermal systems. This experimental and modeling framework provides a novel lens through which to interrogate episodes of interaction between processes originating in the mantle (e.g., LIP eruptions) and their expression in the sedimentary record and their impact on the biosphere throughout Earth history. 